\title{
ASSESSMENT OF GENETIC DIVERSITY IN ALOE GERMPLASM ACCESSIONS FROM INDIA USING RAPD AND MORPHOLOGICAL MARKERS
}

\author{
N. M. C. Nayanakantha ${ }^{1 *}$, B. R. Singh ${ }^{2}$ and A. K. Gupta ${ }^{2}$ \\ ${ }^{1}$ Plant Science Department, Rubber Research Institute of Sri Lanka, Dartonfield, Agalawatta, Sri Lanka \\ ${ }^{2}$ G.B. Pant University of Agriculture and Technology, Pantnagar, 263145, Udham Singh Nagar, \\ Uttaranchal, India
}

Accepted 29 December 2009

\begin{abstract}
Eleven Aloe germplasm accessions; A. vera, A. perryi, A. lotus, A. zeylanicum and seven strains of A. vera available at the Defense Agricultural Research Laboratory (DARL), Pithoragarh, and Medicinal and Aromatic Plant Research Development Centre (MRDC), Pantnagar, Uttaranchal, India were subjected to Random Amplified Polymorphic DNA (RAPD) analysis in relation to morphometric parameters for estimating the extent of diversity within and between species. Morphological evaluation of the 11 accessions for selected characters showed qualitative variation among the accessions studied. The RAPD analysis revealed comparable inter and intra species variation. A total of 192 bands were amplified with 7 primers. Out of 192 bands amplified, 89\% was polymorphic and $10.9 \%$ was unique to a particular accession which made it distinct from all other accessions. Maximum similarity of $61 \%$ was observed between DARL 1 and DARL 3 (A. vera) and minimum similarity of $6.8 \%$ was observed between A. lotus and A. perryi. Thus, Aloe accessions maintained at DARL showed high genetic diversity. The RAPD profiles would be useful in genetic improvement and authentication of species and genotype of this medicinally and economically important genus.
\end{abstract}

Key words: Aloe vera, cluster analysis, genetic similarity

\section{INTRODUCTION}

Aloe, belonging to the family Liliaceae, is a genus of herbaceous and succulents found in tropical and subtropical areas, particularly South Africa and Arabia. Although about 360 species of Aloe have been reported, only Aloe vera (L.) Burm f. (Synonyms : Aloe barbadensis Miller), commonly known as "Komarika" (in Sinhala) and "Ghrith Kumari" (in Hindi), has become naturalized almost in all parts of India (Klein and Penneys, 1988). Aloe vera is the most important among the Aloe species as it has been used medicinally for several thousands of years in folk medicine in many cultures from ancient Egypt, Greece, and Rome to China and India (Kemper and Chiou, 1999).

The plant has stiff, gray-green, lance-shaped leaves containing clear gel in a central mucilaginous pulp. The gel contains an emollient polysaccharide, glucomannan, which is a good moisturizer utilized in many cosmetics (Henry, 1979). Acemannan, the major carbohydrate fraction in the gel demonstrates antineoplastic and antiviral effects (Mc Daniel et al., 1990). The gel also contains bradykininase, an anti-inflammatory, which prevents itching, and salicylic acid and other antiprostaglandin compounds that relieves inflammation (Yagi et al., 1982). Other important pharmacological activities of Aloe vera are anti diabetic (Rajasekaran et al., 2006), antiseptic (Capasso et al., 1998), anti- tumor (Winter et al., 1981) and wound and burn healing effect (Heggers et al., 1993).

Apart from Aloe vera, other economically important species of Aloe include A. ferox Mill., A. Africana Mill., A. perryi Back., A. arborescence Mill., A. zeylanicum, etc. The different species of Aloe have somewhat different concentrations of active ingredients (Yagi et al., 1998). There are morphological variations in some economically important Aloe species (Darokar et al., 2003) and leaf phenolic constitution (Van Der Bank et al., 1995; Viljoen, 1999). However, due to lack of expressions for reproductive characters in some of the species, it is not possible to distinguish them (Reynolds,

*Corresponding author's email: nayanakanthachamil7@gmail.com 
1990). Since morpho-chemical characters are dependent on age and environment, it is essential to characterize this medicinally and economically important genus genetically.

Various molecular markers have been developed as powerful tools for diversity analysis and establishing relationships between species and cultivars. The assessment of genotypic identity among individuals of a species is central to making valid biological interpretations about population structure, breeding systems, reproductive biology and micro evolutionary processes within and among the species. Among various molecular markers, the Random Amplified Polymorphic DNA (RAPD) is most widely used because it allows a rapid and inexpensive assay with different primers (Williams et al., 1990). Due to the technical simplicity and speed of RAPD methodology, it has been successfully used for the assessment of genetic structure and phylogenetic analysis (Gepts, 1993). It has been successfully applied to studies of genetic differentiation in some genera- like Mangifera (Karihaloo et al., 2003); Asparagus (Shasany et al., 2003); Eucalyptus (Keil and Griffin, 1994) and Gossypium (Multani and Lyon, 1995), etc.

In recent years, RAPD technique was used to estimate the genetic diversity in the germplasm collections in Aloe spp. at different institutions (Shioda et al., 2003; Darokar et al., 2003). Thus, the present study was taken to characterize the Aloe germplasm accessions collected from different geographical regions of India and maintained at the Defense Agricultural Research Laboratory (DARL), Pithoragarh, and Medicinal and Aromatic Plant Research Development Centre (MRDC), Pantnagar, Uttaranchal, at molecular level in relation to morphological variation.

\section{MATERIALS AND METHODS}

\section{Plant Material}

Of the available Aloe germplasm accessions at DARL, Pithoragarh, India, nine accessions representing different geographical regions of India were used for the study. These accessions included two species namely $A$. lotus and $A$. perryi and seven strains of $A$. vera viz. DARL 1, DARL 2, DARL 3, DARL 4, DARL 5, DARL 6 and DARL 8. Aloe zeylanicum and commonly grown A. vera obtained from MRDC, Pantnagar, India were also used. All the plants used in the present study were about one year of age.

\section{Morphological characteristics}

Characters such as plant height, leaf length, leaf width and leaf thickness were recorded in all Aloe accessions for comparative studies. Leaf colour was recorded with the help of New Ornamentals Society (NOS) colour chart.

\section{Isolation of DNA}

DNA was isolated from $3 \mathrm{~g}$ of the leaf tissue (excluding the gel like mesodermal region) according to the protocol described by Khanuja et al. (1999) and dissolved in $200 \mu \mathrm{L}$ of high salt TE buffer ( $\mathrm{pH}$ 8.0). For the removal of RNA, $10 \mu \mathrm{g}$ of RNAse A was added to the DNA solution and incubated for 10 minutes at $37^{\circ} \mathrm{C}$. The DNA was then purified by phenol: chloroform extraction and ethanol precipitation. The quantity and purity of the DNA were assessed, checked for quality and purity by electrophoresis in a agarose gel in $1 \mathrm{x}$ TAE buffer (Sambrook et al., 1989). Quantification of DNA was done in UV spectrophotometer (Elico SL 159, India) by measuring optical densities at $260 \mathrm{~nm}$ and the ratio of OD $260 / 280 \mathrm{~nm}$ respectively. Agarose gel electrophoresis $1 \%(\mathrm{w} / \mathrm{v})$ with $\lambda$ DNA standards of known concentrations was also carried out to check quantity and quality of extracted DNA. Finally all DNA samples were diluted to get $50 \mathrm{ng} \mu \mathrm{L}^{-1}$ solutions and were stored at $-20{ }^{0} \mathrm{C}$ for use in RAPD assay.

\section{RAPD assay}

A set of ten decanucleotide random RAPD primers (Life Technology, India) were employed for PCR amplification. The sequence and the GC content of primers are given in Table 1.

Table 1. Sequences and GC content of random 10-mer primers (Life Technology, India) used in the analysis.

\begin{tabular}{c|cc}
\hline Primer & Sequence 5' to 3' & GC content (\%) \\
\hline LC-76 & 5' GTGACGTAGG3' & 60 \\
LC-77 & 5' GGGTAACGCC3' & 70 \\
LC-80 & 5' CAGCACCCAC3' & 70 \\
LC-81 & 5' TCTGTGCTGG3' & 60 \\
LC-82 & 5' TTCCGAACCC3' & 60 \\
LC-83 & 5' AGCCAGCGAA3' & 60 \\
LC-87 & 5' AGGTGACCGT3' & 60 \\
LC-89 & 5' AGTCAGCCAC3' & 60 \\
LC-90 & 5' GTGAGGCGTC3' & 70 \\
LC-91 & 5' TGGACCGGTG3' & 70 \\
\hline
\end{tabular}

DNA amplification was performed in $25 \mu \mathrm{L}$ reaction volume containing $50 \mathrm{ng}$ of genomic DNA, $100 \mu \mathrm{M}$ of each dNTPs, $1.5 \mathrm{mM} \mathrm{MgCl} 2$, $30 \mathrm{ng}$ of each primer, 1 unit of Taq DNA polymerase and $10 \mathrm{X}$ incubation buffer. The content $(25 \mu \mathrm{L}$ in each tube) was gently mixed 
and centrifuged for few seconds. The PCR amplification was achieved in a Biometra $\mathrm{T}$ gradient DNA thermocycler and the cycling conditions were: Initial denaturation at $94^{\circ} \mathrm{C}$ for $5 \mathrm{~min}$ followed by 36 cycles of $94^{\circ} \mathrm{C}$ for $30 \mathrm{sec}$, $41^{0} \mathrm{C}$ for $1 \mathrm{~min}, 72^{\circ} \mathrm{C}$ for $2 \mathrm{~min}$ and finally 1 cycle of $72^{\circ} \mathrm{C}$ for $5 \mathrm{~min}$. $12 \mu \mathrm{L}$ aliquots of amplification products were separated on 1.6 $(\mathrm{w} / \mathrm{v})$ agarose gels containing ethidium bromide $(0.5 \mu \mathrm{g} / \mathrm{mL})$ in $1 \mathrm{X}$ TAE buffer and gels were photographed using an Alpha Image Gel Documentation System. Amplified fragments were scored as presence (1) or absence (0) of individuals. Initially a genetic similarity matrix was constructed using Jaccard's Similarity Coefficient (Sokal and Sneath, 1963). The similarity matrix was subsequently used to construct a tree for cluster analysis by UPGMA (Unweighted Pair Group Method with Arithmetic average) method using the computer package NTSYS 2.1 (Rohlf, 2000).

\section{RESULTS}

\section{Morphometric analysis}

Significant variations were observed for various characteristics studied among Aloe accessions. Aloe zeylanicum was found to be the tallest $(53 \mathrm{~cm})$ as it possesses a distinct stem (caulescent) with long internodes. The leaf shape was linear in this species compared to that of linear-lanceolate shaped leaves in others except A. lotus (Table 2). Minimum leaf thickness ( 0.4 $\mathrm{cm})$ and wideness $(1.0 \mathrm{~cm})$ were recorded in this species among all Aloe accessions and therefore, it contained a lesser amount of gel. Aloe lotus was the shortest plant type with a height of 17 $\mathrm{cm}$. It more or less resembles the common cactus plant in appearance than other Aloe accessions in possessing the ovate-lanceolate shaped and broadest $(4.5 \mathrm{~cm})$ leaves (Table 2 and Fig. 1a, b, c and d).

Among all Aloe accessions, A. perryi was considered as a blue green variety because of its blue-green appearance in leaf (Table 2). It is also a caulescent type plant but the internodal length was low compared to that in A. zeylanicum. Leaf width and size were slightly deviated from other A. vera strains (Fig. 1d).

Among A. vera strains, conspicuous variations were observed in plant height, leaf size, thickness and width while very little variations were observed in leaf colour (Table 2). In terms of leaf thickness, DARL-3 showed the highest thickness $(1.1 \mathrm{~cm})$ than other accessions. These accessions were further subjected to RAPD analysis for the assessment of genetic variation at molecular level.

\section{RAPD analysis}

The RAPDs generated were used to determine the genetic diversity among 11 accessions of Aloe as depicted in Table 3. Out of 10 primers tested, only seven primers $(70 \%)$ generated strong amplification and resulted in informative scorable bands. A total of 192 bands were amplified with an average of 27.4 bands per primer and these were in the size range from $0.15 \mathrm{~kb}-1.5 \mathrm{~kb}$. The individual primers generated bands ranged from 8 (with the primer LC- 91) to a maximum of 44 (with primers LC- 77 and LC83 ) (Table 3).

Out of 192 bands, 171 (89\%) were found to be polymorphic for one or more accessions. The primer LC-77 showed the highest polymorphism of $97 \%$ followed by LC-81 (95\%), LC-76 (93\%) and LC-83 (89\%) respectively (Table 3). Results of the present study revealed an average of $24.4 \%$ polymorphic bands per primer. LC-91 amplified the least polymorphism of $75 \%$. Amplification profiles observed with two primers (LC-77 and LC-83) are shown in Fig. 3a and $b$, respectively.

Twenty one unique (specific to an accession) bands (10.9\%) were also identified. LC-90 amplified maximum number of accessions specific bands of 6 for 3 different accessions while LC-83 and LC-87 amplified maximum number of unique accessions specified bands of 5 and 4, respectively. Moreover, all the seven primers tested produced at least one unique band (Table 3).

Significant inter and intra specific variations could be visualized as evident from the similarity coefficients (Table 4) developed on the basis of relative indices among all possible pairs. Similarity values varied from 0.068 to 0.61 . Maximum similarity of $61 \%$ was observed between DARL 1 and DARL 3 while lowest similarity of $6.8 \%$ was observed between $A$. lotus and A. perryi.

Cluster analysis using UPGMA (Fig. 2) generated from this matrix classified these accessions in to two major clusters. Aloe lotus and $A$. perryi branched out from the main clusters containing other accessions with distant similarity values of $14 \%$ and $21 \%$, respectively. Aloe vera obtained from MRDC distinctly 
formed a major cluster with other $A$. vera strains obtained from DARL with intra-specific diversity ranging from $37 \%$ (for the sub cluster containing DARL 1, 2 and 3) to $45 \%$ (for the sub cluster containing DARL $4,5,6$ ). The other major cluster contained DARL-8 and $A$. zeylanicum. However, a distant relationship with a low similarity value of $30 \%$ was recorded between these two accessions.

Table 2. Morphological description of Aloe accessions used in the present study (Number given for leaf colour is according to New Ornamentals Society (NOS) colour chart).

\begin{tabular}{|c|c|c|c|c|c|c|c|c|}
\hline Accessions & Species & Plant type & $\begin{array}{l}\text { Plant } \\
\text { height } \\
(\mathrm{cm})\end{array}$ & $\begin{array}{c}\text { Leaf } \\
\text { thickness } \\
(\mathrm{cm})\end{array}$ & $\begin{array}{c}\text { Leaf } \\
\text { width } \\
(\mathrm{cm})\end{array}$ & Leaf shape & $\begin{array}{l}\text { Leaf } \\
\text { length } \\
(\mathrm{cm})\end{array}$ & $\begin{array}{l}\text { Leaf } \\
\text { colour }\end{array}$ \\
\hline DARL-1 & A. vera & Acaulescent & 22 & 0.9 & 1.5 & $\begin{array}{l}\text { Linear- } \\
\text { lanceolate }\end{array}$ & 22 & 007000 \\
\hline DARL-2 & A. vera & Acaulescent & 21 & 0.6 & 1.5 & $\begin{array}{l}\text { Linear- } \\
\text { lanceolate }\end{array}$ & 15 & 007000 \\
\hline DARL-3 & A. vera & Acaulescent & 23 & 1.1 & 2.0 & $\begin{array}{l}\text { Linear- } \\
\text { lanceolate }\end{array}$ & 33 & 008000 \\
\hline DARL-4 & A. vera & Acaulescent & 32 & 0.8 & 2.2 & $\begin{array}{l}\text { Linear- } \\
\text { lanceolate }\end{array}$ & 38 & 006000 \\
\hline DARL-5 & A. vera & Acaulescent & 31 & 1 & 1.8 & $\begin{array}{l}\text { Linear- } \\
\text { lanceolate }\end{array}$ & 34 & 004000 \\
\hline DARL-6 & A. vera & Acaulescent & 32 & 0.8 & 1.7 & $\begin{array}{l}\text { Linear- } \\
\text { lanceolate }\end{array}$ & 28 & 007000 \\
\hline DARL-7 & A. perryi & Caulescent & 24 & 0.7 & 1.6 & $\begin{array}{l}\text { Linear- } \\
\text { lanceolate }\end{array}$ & 21 & 004020 \\
\hline DARL-8 & A. vera & Acaulescent & 24 & 0.9 & 1.5 & $\begin{array}{l}\text { Linear- } \\
\text { lanceolate }\end{array}$ & 22 & 004000 \\
\hline $\mathrm{AL}$ & A. lotus & Acaulescent & 17 & 0.9 & 4.5 & $\begin{array}{l}\text { Ovate- } \\
\text { lanceolate }\end{array}$ & 14 & 009000 \\
\hline AV & A. vera & Acaulescent & 30 & 0.9 & 2.5 & $\begin{array}{l}\text { Linear- } \\
\text { lanceolate }\end{array}$ & 46 & 007000 \\
\hline $\mathrm{AZ}$ & A. zeylanicum & Caulescent & 53 & 0.4 & 1.0 & Linear & 24 & 002000 \\
\hline
\end{tabular}

Table 3. List of RAPD primers along with percentage of polymorphism and unique bands detected.

\begin{tabular}{llccccc}
\hline Primer & Sequence (5' to 3') & $\begin{array}{l}\text { Number of } \\
\text { scored } \\
\text { bands }\end{array}$ & $\begin{array}{l}\text { Number of } \\
\text { Polymorphic } \\
\text { bands }\end{array}$ & $\begin{array}{l}\text { Polymorphism } \\
(\%)\end{array}$ & $\begin{array}{l}\text { Number of } \\
\text { Unique } \\
\text { bands }\end{array}$ & $\begin{array}{l}\text { Unique rate } \\
(\%)\end{array}$ \\
\hline LC-76 & GTGACGTAGG & 32 & 30 & 93.7 & 2 & 6 \\
LC-77 & GGGTAACGCC & 44 & 43 & 97.7 & 1 & 2 \\
LC-81 & TCTGTGCTGG & 20 & 19 & 95 & 1 & 5 \\
LC-83 & AGCCAGCGAA & 44 & 39 & 89 & 5 & 11 \\
LC-87 & AGGTGACCGT & 17 & 13 & 76 & 4 & 23 \\
LC-90 & GTGAGGCGTC & 27 & 21 & 77.7 & 6 & 22 \\
LC-91 & TGGACCGGTG & 8 & 6 & 75 & 2 & 25 \\
Total & & 192 & 171 & 89 & 21 & 10.9 \\
Average & & 27.4 & 24.4 & 12.7 & 3 & 1.5 \\
Range & & $8-44$ & $6-43$ & $75-97.7$ & $1-6$ & $1.5-25$ \\
\hline
\end{tabular}


Table 4. Genetic similarity matrix for Jaccard's Coefficient. Accession numbers 1-DARL-1, 2DARL-2, 3-DARL-3, 4-DARL-4, 5-DARL-5, 6-DARL-6, 7- A. perryi, 8 -DARL-8, 9- A. lotus, 10 - A. vera and 11- $A$. zeylanicum.

\begin{tabular}{|c|c|c|c|c|c|c|c|c|c|c|c|}
\hline & 1 & 2 & 3 & 4 & 5 & 6 & 7 & 8 & 9 & 10 & 11 \\
\hline 1 & 1.000 & & & & & & & & & & \\
\hline 2 & 0.529 & 1.000 & & & & & & & & & \\
\hline 3 & 0.610 & 0.434 & 1.000 & & & & & & & & \\
\hline 4 & 0.545 & 0.428 & 0.518 & 1.000 & & & & & & & \\
\hline 5 & 0.409 & 0.285 & 0.357 & 0.590 & 1.000 & & & & & & \\
\hline 6 & 0.375 & 0.160 & 0.290 & 0.480 & 0.478 & 1.000 & & & & & \\
\hline 7 & 0.173 & 0.150 & 0.133 & 0.192 & 0.217 & 0.200 & 1.000 & & & & \\
\hline 8 & 0.214 & 0.153 & 0.242 & 0.310 & 0.346 & 0.423 & 0.240 & 1.000 & & & \\
\hline 9 & 0.133 & 0.153 & 0.108 & 0.151 & 0.250 & 0.156 & 0.068 & 0.085 & 1.000 & & \\
\hline 10 & 0.454 & 0.333 & 0.392 & 0.500 & 0.434 & 0.458 & 0.380 & 0.384 & 0.125 & 1.000 & \\
\hline 11 & 0.083 & 0.093 & 0.121 & 0.162 & 0.176 & 0.105 & 0.161 & 0.303 & 0.162 & 0.205 & 1.000 \\
\hline
\end{tabular}

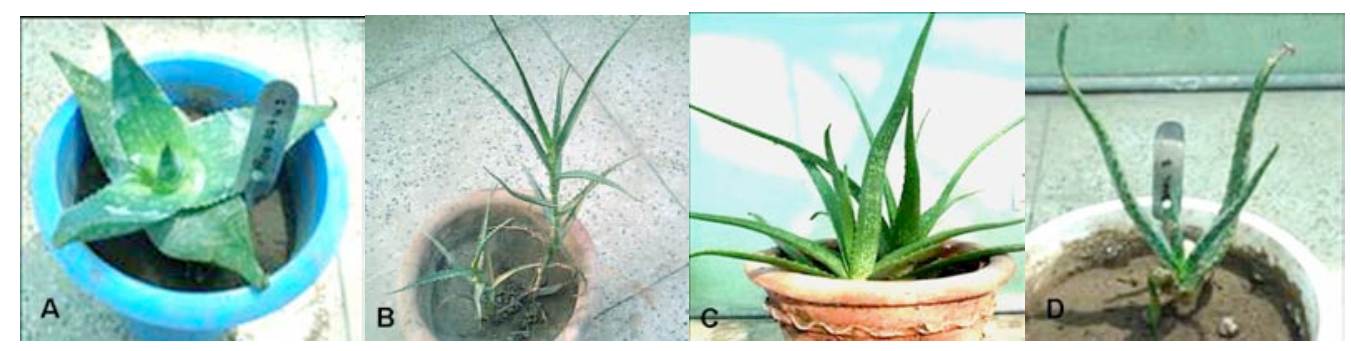

Figure 1. Typical morphotypes shown by four species of Aloe in the germplasm collection. (A): $A$. lotus, (B): A. zeylanicum, (C): A. vera and (D): A. perryi. 


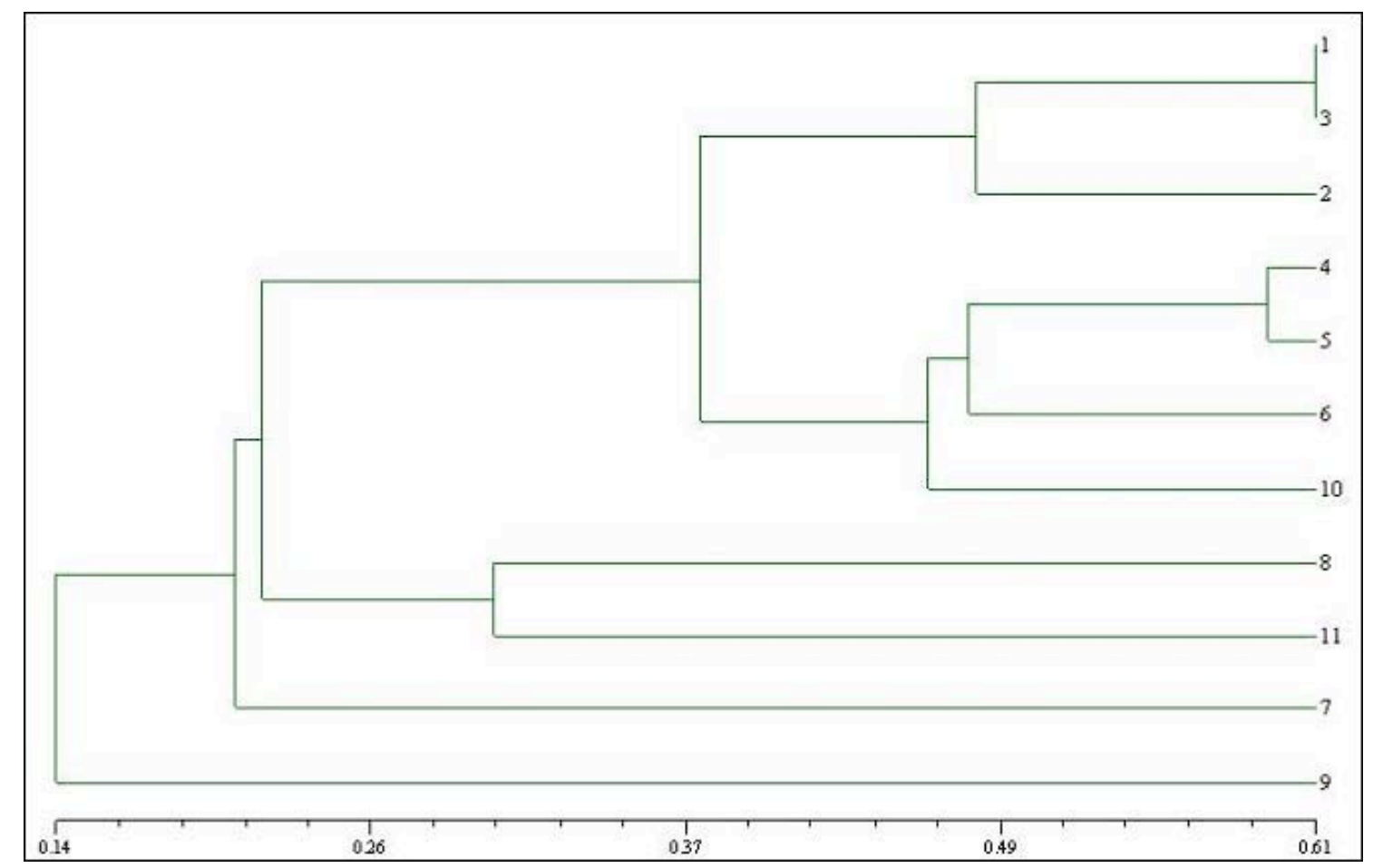

Figure 2. UPGMA cluster analysis-based dendrogram depicting genetic relationships among 11 accessions of Aloe. Accession numbers 1-DARL-1, 2- DARL-2, 3-DARL-3, 4-DARL-4, 5-DARL-5, 6DARL-6, 7- A. perryi, 8 -DARL-8, 9- A. lotus, 10 - A. vera and 11- A. zeylanicum.

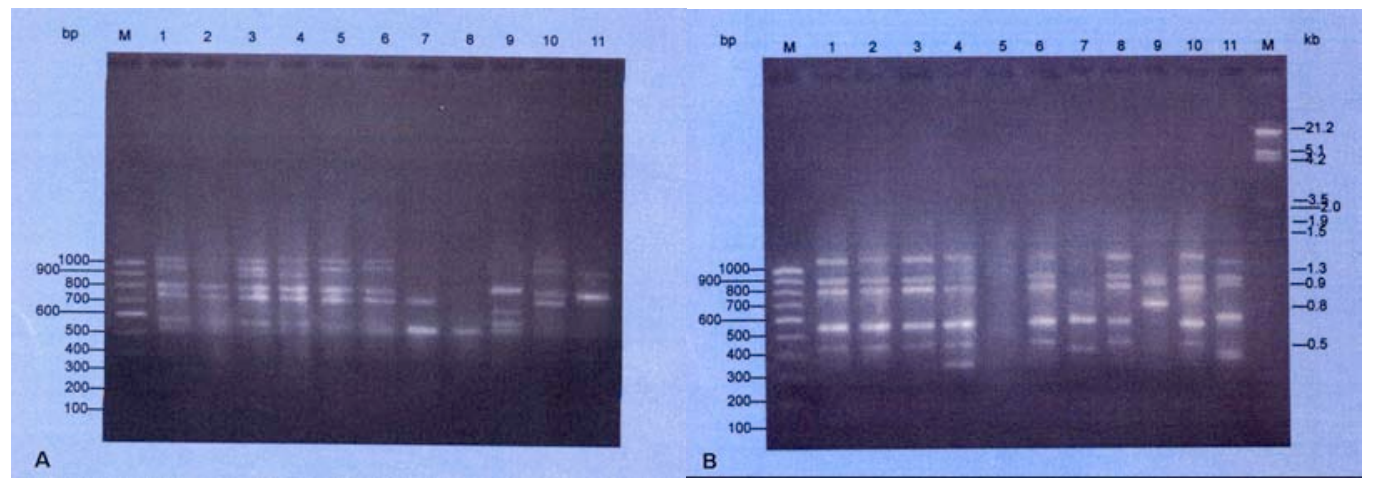

Figure 3. RAPD profiles generated from 11 Aloe accessions with primer LC- 77 (A) and primer LC83 (B). Lanes 1-11 are DARL-1, DARL-2, DARL-3, DARL-4, DARL-5, DARL-6, A. perryi, DARL-8, $A$. lotus, $A$. vera and $A$. zeylanicum respectively. Lane $M$ (left) is 100bp DNA ladder and Lane $M$ (right) is Eco RI + HindIII double digested $\lambda$ DNA. 


\section{DISCUSSION}

In the present study, four Aloe species viz. A. vera, $A$. perryi, A. lotus and A. zeylanicum and seven strains of $A$. vera were studied with some characteristic morphotypic traits but still showing some overlaps across species and strains of A. vera. Aloe zeylanicum and A. perryi were easily separated from other accessions by their distinct stem development. Aloe lotus was also separated with the help of leaf morphology. Although, common A. vera and other strains of A. vera exhibited some variations in height, leaf size, and colour, these could be attributed to the adaptations of their original geographical and environmental conditions.

Vegetative characters being true phenotypic expression show variation, which makes the identification more difficult. Moreover, traditional morphological observations and chemical characters alone cannot determine the roles of phenotypic plasticity and genetic differentiation on population variation and adaptation (Gepts, 1993). Hence, they lack the resolving power needed to identify individual genotypes.

There are other Aloe species which resemble $A$. vera in growth habits and morphological traits (Reynolds, 1966). Moreover, identifying Aloe species at its early stage from other members of the Cactus family is also sometimes ambiguous. Thus, in order to determine genetic variations of these accessions, RAPD markers were used in the present study.

DNA-based markers such as RAPD, are practically unlimited in number, remain unaffected by environment and growth conditions and are simply inherited (Karihaloo et al., 2003). Thus, this RAPD analysis provided phylogenetic relationships as well as some unique DNA bands to quantify the genetic variation.

Out of 10 primers tested, seven primers produced polymorphic bands giving a range of polymorphism from $75 \%$ to $97.7 \%$. Moreover, all the seven primers tested produced at least one unique band. Therefore, higher polymorphism percentage reported in the present study demonstrates the high level of genetic diversity that exists among Aloe accessions maintained at DARL, India. The polymorphism generated by the primers LC-77, LC-81, LC-76 and LC-83 were $97.7 \%, 95 \%, 93 \%$ and $89 \%$, respectively.
The number of unique bands obtained from them were $1,1,2$ and 5 , respectively. On the other hand, the primers LC-90, LC-87 and LC-91 produced unique bands of 6,4 and 2 respectively. Thus, all the seven primers employed in the present study could be effectively used to distinguish Aloe accessions.

The similarity values ranging from $6.8 \%$ to $61 \%$ indicate that there is a remarkable genetic variation among Aloe accessions used in the present study. The highest similarity recorded in the present study was $61 \%$ (between DARL-1 and DARL-3) followed by $59 \%$ (between DARL-4 and DARL-5). Other A. vera strains showed even lesser similarity values with each other and also with common A. vera. Furthermore, these similarity values are par less compared to that with higher similarity $(78.8 \%$ 99\%) recorded among $A$. vera accessions maintained at the Central Institute of Medicinal and Aromatic Plants (CIMAP), Lucknow, India (Darokar et al., 2003). According to them the similarity between $A$. saponaria and A. perryi was $45 \%$ while the similarity between $A$. saponaria and $A$. vera was $47 \%$. Thus, the observed morphological differences and similarity values of $A$. vera strains maintained at DARL suggest that they all possess a genetic diversity to a great extent.

Cluster analysis clearly branched out A. lotus and $A$. perryi from rest of Aloe accessions suggesting that these two are more divergent from other accessions. Hence, phenotypic characters combined with RAPD analysis provided a better relationship to identify these species. Aloe zeylanicum formed a separate cluster with DARL-8 but with a distanced similarity of $30 \%$. This cluster combined with the other major clusters containing $A$. vera and strains of $A$. vera (from DARL 1 to 6 ) with a distanced similarity of $21 \%$. Thus, it is evident that A. zeylanicum is also more divergent from $A$. vera in the cluster analysis. However, the strains of A. vera (from DARL 1 to 6) showed a closest relationship to the common $A$. vera than to the other Aloe species suggesting that they all might have originated from $A$. vera but grown in different geographical localities in India. However, strain DARL-8 should be paid special attention as it deviated from rest of $A$. vera strains.

RAPDs amplify randomly across the genome. Since the majority of the genome is composed of non-coding regions, one would expect the majority of RAPD markers to be 
amplified from them. These regions have higher random mutation rates and may have only a few phenotypic consequences (Wen and Hsiao, 2001). The RAPD technique provides a useful approach for evaluating genetic differentiation, particularly in those species that are poorly known genetically and are propagated vegetatively such as Musa (Bhat and Jarret, 1995) and Lilium (Haruki et al., 1998). Not only the extent of variation but also RAPD provides markers even for cultivar identification (Torres et al., 1993) and germplasm evaluation (Shioda et al., 2003; Darokar et al., 2003).

Apparently, the present work constitutes the first application of RAPD markers for diversity analysis in A. zeylanicum and A. lotus in relation to $A$. perryi and $A$. vera. In the present study, highly reproducible amplification profiles produced under constant conditions suggested that RAPD markers reveal sufficient genetic diversity and a high level of genetic polymorphism among Aloe accessions evaluated. The RAPD technique is therefore expected to be useful in detecting small genetic variations within and among populations. However, detailed morphological study is also desirable in order to understand all aspects of this variation.

The species specific bands that could be identified in this study will provide tags for future genetic improvement as well as in authenticating the species and genotypes and hence an important tool for molecular systematic in this important genus.

\section{ACKNOWLEDGEMENTS}

The authors acknowledge the Sri Lanka Council for Agricultural Research Policy for the financial support. We are thankful to Dr. H. K. Pandey of the Defense Institute of Bioenergy Research (DIBER), Haldwani for granting permission to utilize the Aloe accessions maintained at the Defense Agricultural Research Laboratory (DARL), Pithoragarh. We also thank Mr. M. Arif of the Pathology Department, G.B. Pant University of Agriculture and Technology, Pantnagar, for computer analysis of the data.

\section{REFERENCES}

Bhat, K.V, and Jarret, R.I. (1995). Random Amplified Polymorphic DNA and genetic diversity in Indian Musa germplasm. Genetic Resources and Crop Evolution 42:107-118.

Capasso, F., Borrelli, F. and Capasso, R. (1998). Aloe and its therapeutics use. Phytotherapy Research 12: 121-127.

Darokar, M.P., Rai, R., Gupta, A.K., Shasany, A.K., Rajkumar, S., Sundaresan, V. and Khanuja, S.P.S. (2003). Molecular assessment of germplasm diversity in Aloe species using RAPD and AFLP analysis. Journal of Medicinal and Aromatic Plant Sciences 25: 354361.

Gepts, P. (1993). The use of molecular and biochemical markers in crop evolution studies. In: Evolutionary Biology, M. K. Hecht (Ed.), Plenum press, New York, 27: 51-94.

Haruki, K., Hosoki, T. and Nako, Y. (1998). RAPD analysis of Lilium japonicum Thunb. Native to Shimane and other prefectures (Japan). Journal of the Japanese Society for Horticultural Science (Japan) 67(5): 785-791.

Heggers, J., Pelley, R. and Robson, M. (1993). Beneficial effects of Aloe in wound healing. Phytotherapy Research 7: S48-S52.

Henry, R. (1979). An updated review of Aloe vera. Cosmetics and Toiletries 94: 42-50.

Karihaloo, J. L., Dwivedi, K., Archak, S. and Gaikwad, A. B. (2003). Analysis of genetic diversity of Indian mango cultivars using RAPD markers. Journal of Horticultural Science \& Biotechnology 78(3): 285-289.

Keil, M. and Griffin, A. R. (1994). Use of random amplified polymorphic DNA (RAPD) markers in the discrimination and verification of genotypes in Eucalyptus. Theoretical and Applied Genetics 89: 442-450.

Kemper, K. J. and Chiou, V. (1999). Aloe vera: The Longwood Herbal Task Force and The Center for Holistic Pediatric Education and Research, Pp. 1-29.

Khanuja, S. P. S., Shasany, A. K., Darokar, M. P. and Kumar, S. (1999). Rapid isolation of DNA from dry and fresh samples of plants producing large amounts of secondary metabolites and essential oils. Plant Molecular Biology Reporter 17: 1-7. 
Klein, A. D., Penneys, N. S. (1988). Aloe vera. Journal of American Academy of Dermatology 18: $714-720$.

Mc Daniel, H., Carpenter, R., Kemp, M., Kahlon, J. and Mc Analley, B. (1990). Extended survival and prognostic criteria for Acemannan (ACE-M) treated HIV Patients. Antiviral Research 1: 117.

Multani, D. S. and Lyon, B. R. (1995). Genetic fingerprinting of Australian cotton cultivars with RAPD markers. Genome 38: 1005-1008.

Rajasekaran, S., Sivagnanam, K. and Subramanian, S. (2006). Modulatory effects of Aloe vera leaf gel extract on oxidative stress in rats treated with steptozotocin. Journal of Pharmacy and Pharmacology 57 (2): 241-246.

Reynolds, G.W. (1966). The Aloes of Tropical Africa and Madagascar. The Aloes Book Fund, Mbabane, Swaziland.

Reynolds, T. (1990). Comparative chromatographic patterns of leaf exudate components from shrubby aloes. Botanical Journal of Linnaean Society 102: 273-285.

Rohlf, F. J. (2000). NTSY-pc Numerical Taxonomy and Multivariate Analysis System. Exter Publication, Setauket, New York, USA. Pp. 33 .

Sambrook, J., Fritsch, E.F. and Maniatis, T. (1989). Molecular cloning: A laboratory Manual. Cold Spring Harbor Laboratory, New York. $2^{\text {nd }}$ Edn.

Shasany, A. K., Darokar, M. P., Saikia, D., Rajkumar, S., Sundaresan, V. and Khanuja, S. P. S. (2003). Genetic diversity and species relationship in Asparagus spp. Using RAPD analysis. Journal of Medicinal and Aromatic Plant Sciences 25(3): 698-704.

Shioda, H., Kanako, S., Fumiko, N., Tomoko, O., Takako, S., Tomoko, H. and Itsu, K. (2003). Identification of Aloe species by RAPD analysis. Shokuhin Eiseigaku Zasshi 44(4): 203-207.

Sokal, R. R. and Sneath, P. H. A. (1963). Principles of Numerical Taxonomy. Freeman, San Francisco.

Torres, A.M., Millan, T. and Cubero J. I. (1993). Identifying Rose Cultivars using Random
Amplified Polymorphic DNA markers. Hort Science 28: 333-334.

Van Der Bank, H., Van Wyk B. E. and Van Der Bank, M. (1995). Genetic variation in two economically important Aloe species (Aloaceae). Biochemical Systematics and Ecology 23: 251256.

Viljoen, A.M., Van Wyk, B.E. and Van Heerden, F.R. (1999). The chemotaxonomic value of two cinnamoyl chromones, aloeresin $\mathrm{E}$ and F in Aloe (Aloaceae). Taxon 48: 747-754.

Wen, H. and Hsiao, L. (2001). Altitudinal Genetic Differentiation and Diversity of Taiwan Lily (Lilium longiflorum var. formosanum; Liliaceae) Using RAPD Markers and Morphological Characters. International Journal of Plant Science 162(2): 287-295.

Williams, J. K. F., Kubelik, A. R., Livak, K. G., Rafalki, J. A. and Tingey, S. V. (1990). DNA polymorphisms amplified by arbitrary primers are useful as genetic markers. Nucleic Acids Research 18: 6531-6535.

Winter, W. D., Benavides, R. and Clouse, W. J. (1981). Effects of Aloe extracts on human normal and tumor cells in vitro. Economic Botany 35: 89-95.

Yagi, A., Harada, N., Yamada, H. and Iwadare, S. I. N. (1982). Antibradykinin active material in Aloe saponaria. Journal of Pharmaceutical Sciences 71: 1172-1174.

Yagi, A., Tsunoda, M., Egusa, T., Akasaki, K. and Tsuji, H. (1998). Immunochemical distinction of Aloe vera, A. arborescens, and $A$. chinensis gels [letter]. Planta Medica 64: 277278. 